\section{SIMULASI RESPON PONDASI TIANG PANCANGAKIBAT PEMBEBANAN LATERAL MENGGUNAKAN METODE BEDA HINGGA}

\author{
Ahmad Fitri Sujatmiko \\ tenaga ahli PT Surya Unggul Nusa Consultan, Madiun \\ miko_umm@yahoo.com
}

\section{ABSTRACT}

Structural response of concrete of pillar commonly happened from the result of in site test through loading test. But, the test needs large amount. So, it is suggested to use an efficient analysis method through simulation of numeric model. A model of pillar on the homogeny land will be loaded by a horizontal weight. By considering strengthen of the pillar and the reaction of the ground, to solve the accountability can be done by using finite differences method. For example, for a concrete of pillar $30 \times 30 \mathrm{~cm}$ with a lateral weight $1000 \mathrm{~kg}$ are have lendutan response $y_{\text {maks }}=42 \mathrm{~mm}$, while the maximum moment response $M=780 \mathrm{~kg} . \mathrm{m}$

Keyword: concrete response, lateral weight, finite differences method.

\section{PENDAHULUAN} pembebanan (loading test) secara
dengan simulasi model matematis.
Untuk mengetahui respon struktur pondasi tiang pancang, dapat dilakukan dengan serangkaian test pembebanan (loading test) secara eksperimental atau

Dalam studi ini, akan difokuskan pada kajian hipotetik simulasi model pondasi tiang pancang dalam menerima beban lateral menggunakan metode beda hingga (finite difference method). Untuk menyelesaikan formulasi persamaan numeris, digunakan program bantu spreadsheet MS Excel.

Dengan pendekatan simulasi model numerik ini, akan diperoleh respon pondasi tiang pancang berupa lendutan $\left(\mathrm{y}_{\mathrm{i}}\right)$ dan momen $\left(\mathrm{M}_{\mathrm{i}}\right)$ pada tiap kedalaman yang sudah ditentukan. Akan dikaji pula perilaku respon pondasi tiang pancang untuk berbagai bentuk penampang sebagaimana pada gambar berikut:

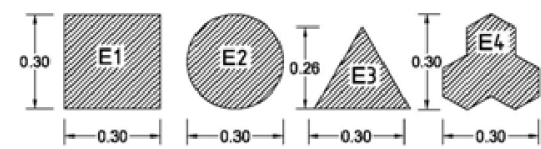

Gambar 1. Penperilaku respon pondasi tiang pancang

Dari kajian ini diharapkan menjadi referensi praktis bagi para insinyur dan akademisi untuk mengetahui respon pondasi tiang pancang yang telah dirancangnya secara analitis.

\section{METODELOGI PENELITIAN}

Pondasi tiang pancang yang akan dikaji merupakan pondasi minipile dari beton dengan mutu $\mathrm{f}_{\mathrm{C}=20 \mathrm{MPa}}$. Nilai modulus elastisitasnya sesuai dengan SNI 03-2847-2002 (Tata Cara Perhitungan Struktur Beton) adalah sebesar $\mathrm{E}=4700$ Öfc

Adapun momen inersia disesuaikan dengan berbagai bentuk penampang yang ada. Selengkapnya disajikan pada table berikut.

Dari konsep pondasi WINKLER, reaksi tanah diidealisasi sebagai titik-titik pegas yang bekerja di sepanjang balok tiang pancang. Sebagai contoh, balok tiang pancang dibagi menjadi 4 elemen dengan 5 node sejarak $\mathrm{h}$ yang konstan seperti pada gambar 2 berikut.

\begin{tabular}{lc} 
Penampang pondasi & Inersia \\
\hline E1=segi empat & $1 / 12 \cdot b \cdot h^{3}$ \\
E2=Lingkaran & $1 / 2 \cdot r \cdot r^{3}$ \\
E3=Segi tiga & $1 / 36 \cdot b \cdot h^{3}$ \\
E4=tripod & $\sum 1 / 12 \cdot b \cdot h^{3}$
\end{tabular}

96 |Media Teknik Sipil, Volume 9, Nomor 2, Agustus 2011: 96 - 101
Tabel 1. Momen inersia penampang
Pada studi ini, tanah disekitar pondasi dimodelkan sebagai system pegas (spring) denga kekakuan ks, menggunakan teori WINKLER mengenai ekuivalen pegas. Tanah tersebut merupakan tanah homogen dengan nilai koefien tanah dasar yang seragam di setiap lapisan tanah. Dari penelitian Hari Cristadi (2009), diperoleh nilai modulus tanah dasa $\mathrm{ks}=4993 \mathrm{KN} / \mathrm{m}^{3}$.

\section{Metode Beda Hingga}

Pondasi tiang pancang diidealisasikan sebaga sebuah balok sepanjang sumbu $\mathbf{x}$ dengan penampan yang konstan disepanjang balok. Pada ujung tian diberi beban lateral (P) pada arah sumbu $\mathbf{y}$ Perpindahan pada arah sumbu $\mathbf{y}$ adalah $\mathrm{y}_{\text {, dan momen }}$ lentur adalah M. Dari teori mekanika bahan didapa persamaan:

$$
E I \frac{d^{2} y}{d x^{2}}=-M
$$

Dengan menggunakan formulasi beda hingg diferensial orde 2, Chapra (1991), dimana dx adala $\mathrm{h}$, persamaan (1) dapat ditulis lagi sebagai berikut Bowles (1975);

$$
\begin{aligned}
& \frac{E I}{h^{2}}\left(y_{n-1}-2 y_{n}+y_{n+1}\right)=-M \\
& \frac{E I}{h^{2}}=C \\
& C\left(y_{n-1}-2 y_{n}+y_{n+1}\right)=-M
\end{aligned}
$$

Dari konsep pondasi WINKLER, reaksi tanah diidealisasi sebagai titik-titik pegas yang bekerja sepanjang balok tiang pancang. Sebagai contoh, balok tiang pancang dibagi menjadi 4 elemen dengan 5 node sejarak h yang konstan seperti pada gambar 2 berikut.

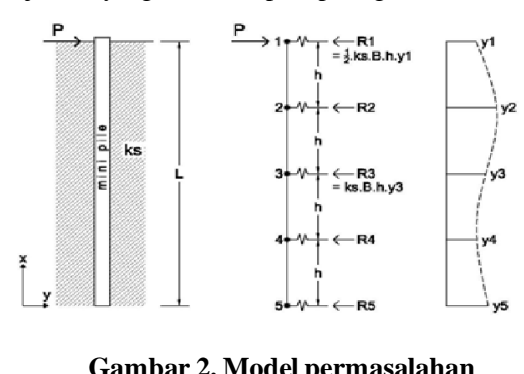

Gambar 2. Model permasalahan
Adapun reaksi tanah di sepanjang balok tiang pancang pada node beda hingga adalah sebagai berikut;

$R_{1}=1 / 2 \mathrm{ks} \cdot \mathrm{B} \cdot \mathrm{h} \cdot \mathrm{y}_{1}$

$\mathrm{ks}_{\mathrm{i}} \cdot \mathrm{B}, \mathrm{h}, \mathrm{y}_{\mathrm{i}}$

$\mathrm{R}_{5}=1 / 2 \mathrm{ks}$. B . h . $\mathrm{y}_{\mathrm{s}}$

Dimana;

$\mathrm{R}_{\mathrm{i}}=$ Reaksi tanah pada tiap node

$\mathrm{ks}=$ modulus tanah dasar

$\mathrm{B}=$ Lebar pondasi tiang pancang

$\mathrm{h}=$ Jarak tiap node

$\mathrm{y}_{\mathrm{i}}=$ perpindahan tiap node

Selanjutnya adalah mengurai reaksi tiap node berdasarkan kesetimbangan gaya " $\mathrm{M}=0$ dan " $\mathrm{F}=0$. Berdasarkan persamaan (4) maka reaksi pada tiap node seperti pada persamaan berikut;

Node 2, " $\mathrm{M}_{2}=0$

$C\left(y_{1}-2 y_{2}+y_{3}\right)+R_{1} \cdot h-P . h=0$

Node 3 , " $\mathrm{M}_{3}=0$

$C\left(y_{2}-2 y_{3}+y_{4}\right)+R_{1} \cdot 2 h+R_{2} \cdot h-P .2 h=0 \ldots$ (9)

Node $4, " \mathrm{M}_{4}=0$

$C\left(y_{3}-2 y_{4}+y_{5}\right)+R_{1} \cdot 3 h+R_{2} \cdot 2 h+R_{3} \cdot h-P \cdot 3 h=0$ (10)

Node 5 , " $\mathrm{M}_{5}=0$

$R_{1} \cdot 4 h+R_{2} \cdot 3 h+R_{3} \cdot 2 h+R_{4} \cdot h-P .4 h=0 \quad . .(11)$

$R_{1}+R_{2}+R_{3}+R_{4}+R_{5}-P=0 . .(12)$

Dari persamaan (8) sampai (12) akan didapat kan 5 persamaan simultan dengan 5 variabel $\left(\mathrm{y}_{\mathrm{i}}\right)$ yang belum diketahui. Penyelesaian dari persamean in menggunakan metode matrik sebagai berikut. $[\mathrm{A}] \mathrm{x}\{\mathrm{yi}\}=\{\mathrm{B}\}$ Atau

$\{\mathrm{yi}\}=[\mathrm{A}]^{-1} \mathrm{x}\{\mathrm{B}\}$

Dimana;

$[\mathrm{A}]=$ matrik konstanta lendutan (yi)

$[\mathrm{A}]^{-1}=$ matrik invers konstanta lendutan (yi)

$\{\mathrm{yi}\}=$ vektor lendutan (yi) pada tiap node

Ahmad Fitri Sujatmiko, Simulasi Respon Pondasi Tiang Pancang Akibat Pembebanan Lateral 97 Menggunakan Metode Beda Hingga 
yang akan dicari

$\{B\}=$ vektor konstanta persamaan

Setelah nilai lendutan $\left(\mathrm{y}_{\mathrm{i}}\right.$ ) diketahui pada masingmasing node, dengan menggunakan persaman (4) akan diperoleh Momen pada tiap node $\left(\mathrm{M}_{\mathrm{i}}\right)$.

\section{Tabel 2. Data perhitungan}

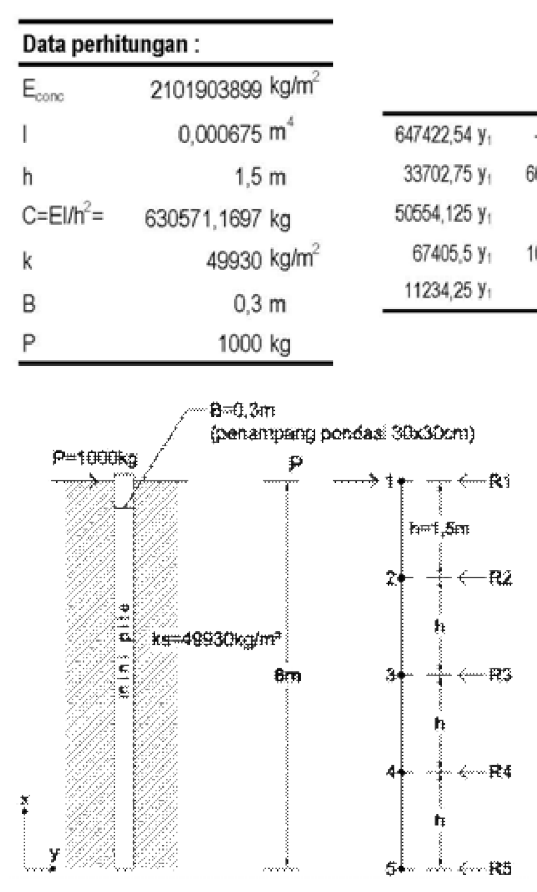

Gambar 3. Pemodelan permasalahan

Langkah pertama adalah menghitung reaksi tanah $(\mathrm{R} i)$ pada tiap node yang sudah ditentukan.

Tabel 3. Perhitungan reaksi tanah (Ri)

\begin{tabular}{llr}
\hline \multicolumn{3}{l}{ Perhitungan Reaksi (Ri) } \\
\hline$R_{1}$ & $0,5 \cdot$ K. B. h. $y_{1}$ & $11234,25 \cdot y_{1}$ \\
$R_{2}$ & k. B. h. $y_{2}$ & $22468,5 y_{2}$ \\
$R_{9}$ & k. B. h. $y_{3}$ & $22468,5 y_{3}$ \\
$R_{4}$ & k. B. h. $y_{4}$ & $22468,5 \cdot y_{4}$ \\
$R_{5}$ & $0,5$. K. B. h. $y_{5}$ & $11234,25 \cdot y_{5}$ \\
\hline
\end{tabular}

98 |Media Teknik Sipil, Volume 9, Nomor 2, Agustus 2011: 96 - 101

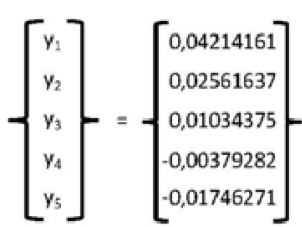

Setelah didapat nilai lendutan (y) pada tiap node, maka dengan persamaan (4) akan diperoleh nilai momen (M.) di tiap node juga.

Selanjutnya dengan langkah perhitungan seperti pada contoh di atas, maka bisa disimulasi berbaga bentuk profil penampang tiang pancang terhadap respon lendutan dan momen yang terjadi.

\section{HASIL DAN PEMBAHASAN}

Dari hasil perhitungan, didapatkan respon endutan dan momen tiap node yang disajikan dalam table dan grafik berikut

Tabel 5. Kedalaman pondasi dan lendutan

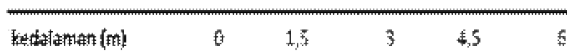

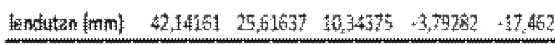

$$
C\left(y_{1}-2 y_{2}+y_{3}\right)+R_{1} \cdot h-P . h=0
$$

$630571,2\left(\mathrm{y}_{1}-2 \mathrm{y}_{2}+\mathrm{y}_{3}\right)+11234,25 \mathrm{y}_{1} \cdot 1,5-1000.1,5=0$

$647422,5 \mathrm{y}_{1}-1261142,3 \mathrm{y}_{2}+630571,2 \mathrm{y}_{3}=1500$

\section{Tabel 4. persamaan simultan tersebut}

disederhanakan menjadi bentuk matrik sebagai berikut:

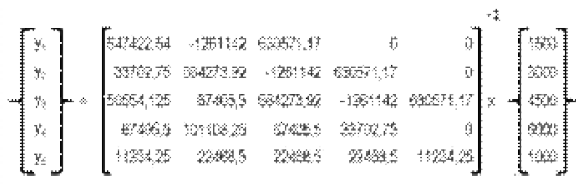

Dengan mengunakan bantuan software spreadsheet MS Excel akan diperoleh nilai y dalam bentuk vector matrik sebagai berikut.

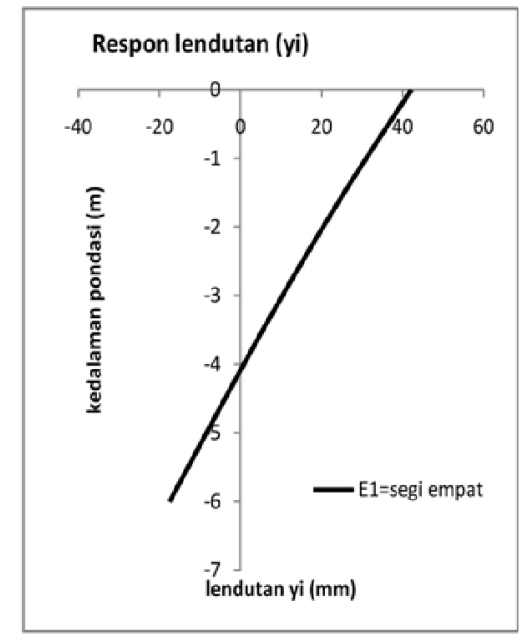

Gambar 4. Grafik hubungan kedalamanlendutan

\begin{tabular}{|c|c|c|c|c|}
\hline 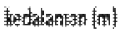 & $\pi$ & 1,4 & \pm & i. 5 \\
\hline 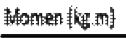 & t & 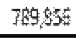 & 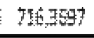 & 294,2706 \\
\hline
\end{tabular}

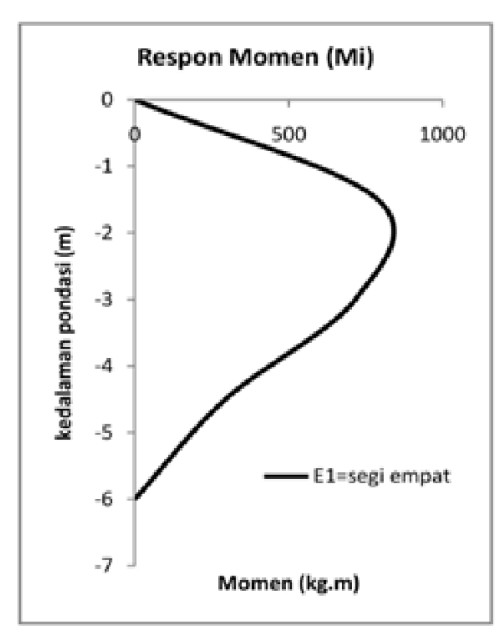

Gambar 5. Grafik hubungan kedalamanmomen

Dari hasil simulasi terlihat bahwa lendutan maksimum akibat beban lateral sebesar 1000kg adalah sebesar $42 \mathrm{~mm}$. Sedangkan momen maksimum yang terjadi adalah sebesar $780 \mathrm{~kg} . \mathrm{m}$ pada kedalaman $1,5 \mathrm{~m}$ dari permukaan tanah.

Pembahasan selanjutnya adalah membanding kan respon lendutan dan momen berbagai bentuk profil penampang tiang pancang. Dengan langkah perhitungan analog dengan perhitungan untuk profil penampang segi empat diatas, maka hasil simulasi untuk profil yang lainnya disajikan dalam tabel dan grafik berikut.

Dengan membandingkan berbagai profil penampang tiang pancang, akan diketahui hubungan antara kekakuan (EI) dan respon struktur.

Ahmad Fitri Sujatmiko, Simulasi Respon Pondasi Tiang Pancang Akibat Pembebanan Lateral | Menggunakan Metode Beda Hingga 


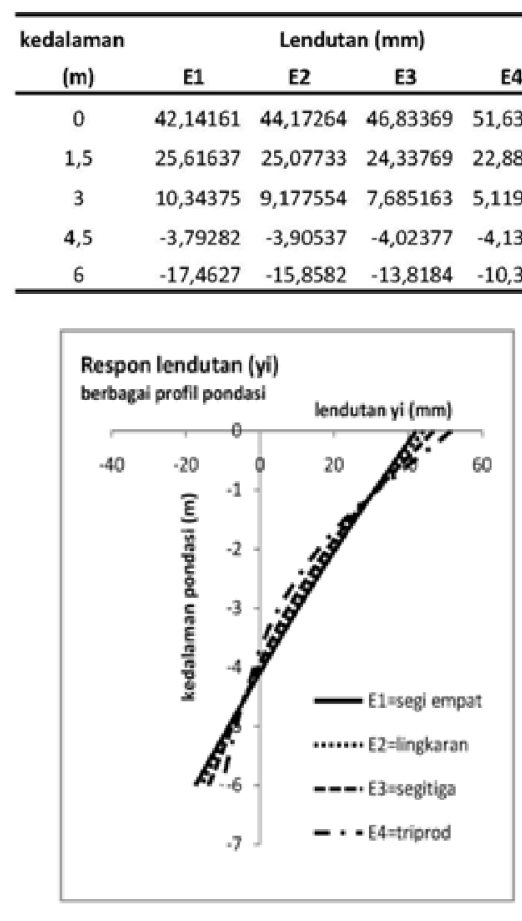

Gambar 6. Grafik hubungan kedalamanlendutan berbagai penampang tiang pancang

Simpangan lendutan maksimum berbagai penampang tiang pancang adalah 51,6mm. Dari grafik terlihat bahwa semakin kecil kekakuan pondasi tiang pancang, maka respon lendutan membentuk fungsi lengkung.

\section{Tabel 8. Kedalaman pondasi dan momen} berbagai

\begin{tabular}{crrrr}
\hline $\begin{array}{c}\text { kedalaman } \\
(\mathbf{m})\end{array}$ & \multicolumn{5}{c}{ E1 } & \multicolumn{1}{c}{ E2 } & \multicolumn{1}{c}{ E3 } & E4 \\
\hline 0 & 0 & 0 & 0 & 0 \\
1,5 & 789,856 & 755,6302 & 710,7879 & 629,936 \\
3 & 716,3697 & 666,0855 & 601,3286 & 488,4888 \\
4,5 & 294,2706 & 267,232 & 232,8582 & 174,507 \\
6 & 0 & 0 & 0 & 0 \\
\hline
\end{tabular}

100 |Media Teknik Sipil, Volume 9, Nomor 2, Agustus 2011: 96 - 101

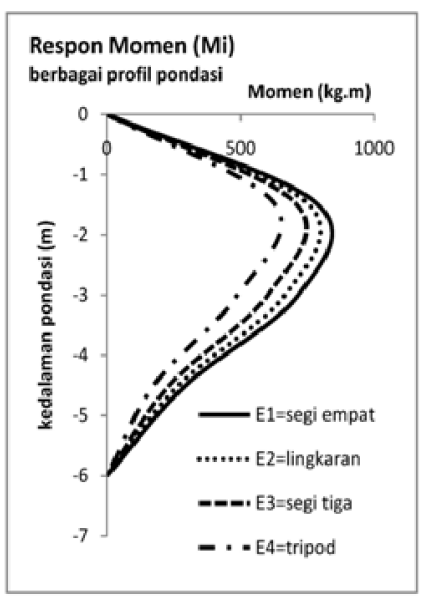

Gambar 7. Grafik hubungan kedalamanmomen berbagai penampang tiang pancang

Respon momen maksimum berbagai penampan tiang pancang adalah $780 \mathrm{~kg} . \mathrm{m}$. Dari grafik terlihat bahwa semakin kecil kekakuan struktur (EI) respon momen yang terjadi juga semakin kecil.

\section{KESIMPULAN DAN SARAN}

1. Dari simulasi, pada pembebebanan latera $1000 \mathrm{~kg}$ respon lendutan maksimum sebesa $42 \mathrm{~mm}$ dan momen maksimum sebesa $780 \mathrm{~kg} . \mathrm{m}$.

2. Respon berbagai penampang tiang pancang dengan dimensi yang setara, salah satunya dipengaruhi oleh kekakuan struktur (EI) Semakin kecil kekakuan, respon lendutan membentuk fungsi lengkung sedangkan respon momen semakin kecil

\section{DAFTAR PUSTAKA}

A. Avaei, Abdoul R. Ghotbi and M. Aryafar, 2008 Investigation of Pile- Soil Interaction Subjecte to Lateral Loads in Layered Soils, American Journal of Engineering and Applied Sciences 1 (1): $76-81$
Anonim, 2003, SNI 03-2847-2002 (Tata Cara Perhitungan Struktur Beton), Jakarta

Bowles, 1975, Solution to Beam on Elastic Foundation Using Finite Differences, Van Nostrand Reinhold Co., New York

Basu, D. and R. Salgado, 2007. Elastic analysis of laterally loaded pile in multi-layered soil. Journal Geomech. Geoeng., 2(3): 183-196, doi:10.1080/1748 6020701401007.

Paulos and E H Davis, 1980, Pile Foundation Analisys and Design, John Willey and Sons, New York.

Popov, E.P, 1984, Mekanika Teknik (ter-jemahan), Penerbit Erlangga, Jakarta

S. Chapra \& RP Canale, 1991, Metode Numerik untuk Teknik (terjemahan), UI Press, Jakarta

Shen, W.Y. and C.I. Teh, 2004. Analysis oflaterally loaded piles in soil with stiffnessincreasing with depth. J. Geotech. and Geoenvir.Engrg., 130(8): 878-882, doi:10.1061/(ASCE)10900241(2004)130:8(878)

Ugural, A. C., and Fenster, S. K. ,1975, Advanced Strength and Applied Elasticity, Elsevier, New York

Yang, K. and R. Liang, 2006. Numerical solution for laterally loaded piles in a two-layer soil profile. Journal Geotech. and Geoenvir. Engrg. 132(11):1436-443, doi:10.1061/(ASCE) 10900241(2006)132:11(1436).Yang Z. and 10. Je24. 2002. Numetict B. Jereni, 2002. Numerical analysis of pile behaviour under lateral loads in layered elasticplastic soils, Int Journal Numeric Analysis Methods in Geomechanics,26(14): 13851406,doi:10.1002/ nag. 250

Ahmad Fitri Sujatmiko, Simulasi Respon Pondasi Tiang Pancang Akibat Pembebanan Lateral | 101 Menggunakan Metode Beda Hingga 